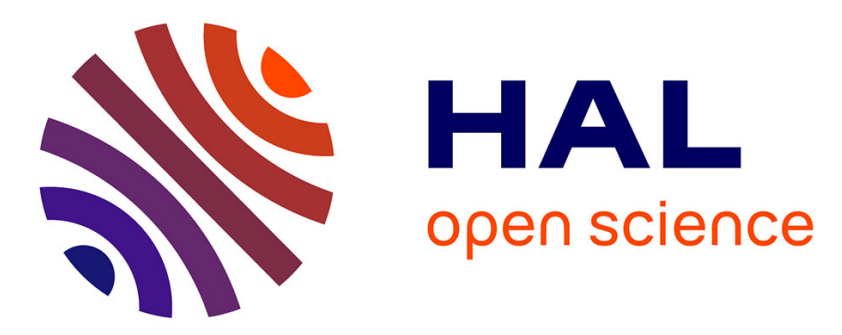

\title{
High speed experimental analysis of orthogonal planing using high speed infrared camera
}

Pierrick Guégan, Arnaud Poitou, Pierre Brémond

\section{To cite this version:}

Pierrick Guégan, Arnaud Poitou, Pierre Brémond. High speed experimental analysis of orthogonal planing using high speed infrared camera. ThermoSense XXVIII, 2006, Orlando, United States. $10.1117 / 12.667568$. hal-01008252

\section{HAL Id: hal-01008252 \\ https://hal.science/hal-01008252}

Submitted on 23 Jun 2018

HAL is a multi-disciplinary open access archive for the deposit and dissemination of scientific research documents, whether they are published or not. The documents may come from teaching and research institutions in France or abroad, or from public or private research centers.
L'archive ouverte pluridisciplinaire HAL, est destinée au dépôt et à la diffusion de documents scientifiques de niveau recherche, publiés ou non, émanant des établissements d'enseignement et de recherche français ou étrangers, des laboratoires publics ou privés. 


\title{
High speed experimental analysis of orthogonal planing using high speed infrared camera
}

\author{
Pierrick Guégan $^{\mathrm{a}}$, Arnaud Poitou ${ }^{\mathrm{a}}$, Pierre Brémond ${ }^{\mathrm{b}}$ \\ a Institut de Recherche en Génie Civil et Mécanique, UMR CNRS 6183, \\ Ecole Centrale de Nantes, 1 rue de la Nö̈, BP 92101, 44321 Nantes Cedex 3, France \\ ${ }^{\mathrm{b}}$ CEDIP Infrared Systems, \\ 19 Boulevard G. Bidault, 77183 Croissy Beaubourg, France
}

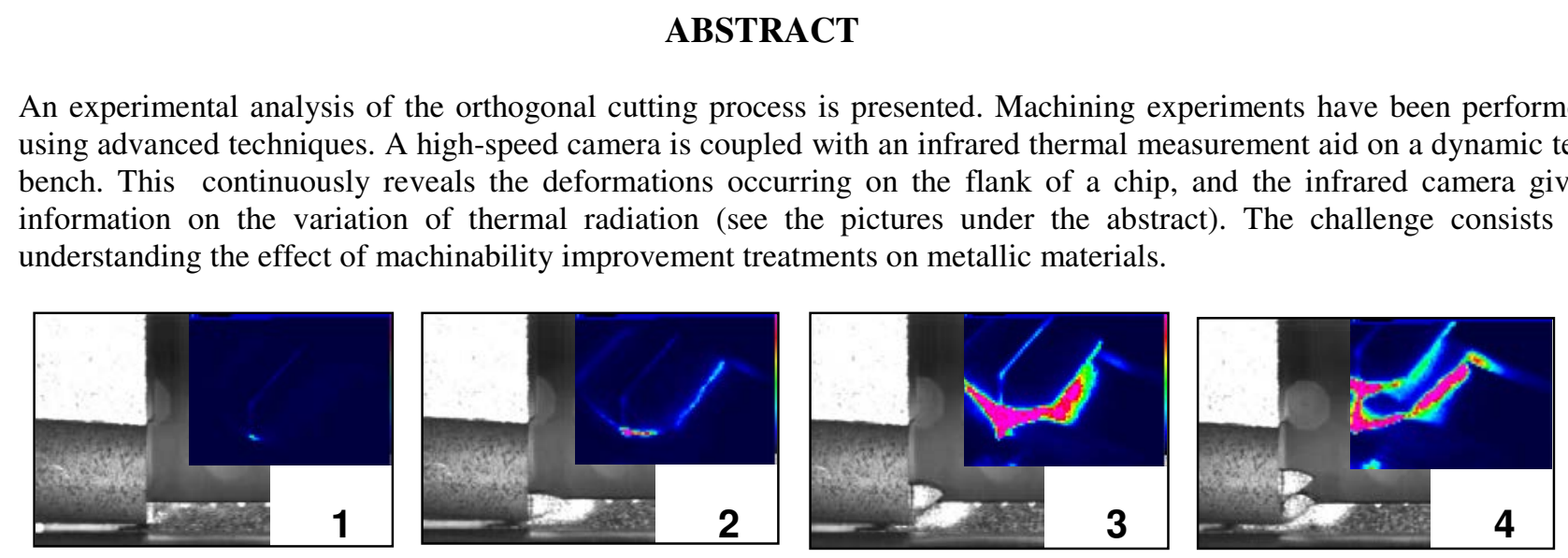

Keywords: High speed infrared camera, high-speed machining, orthogonal cutting, machinability

\section{INTRODUCTION}

Recent studies in the field of machining simulation make possible the creation of numerical tools, to simulate continuous or segmented chip formation [1]. These tools allow computation of the different criteria observed during the chip's formation (temperature, strain distribution, shear bands, etc). The validation of these numerical tools uses the experimental results of stopped tests or punctual observations [2, 3, 5, and 7]. A new method of experimental investigation is being developed on the crossbow system of Ecole Centrale de Nantes. The aim of this study is to reveal continuously the thermal phenomena and the associated strain distribution during an orthogonal cutting chip generation. A direct method is to use a thermal imaging focal-plane-array for spatially resolved non contact temperature measurements especially under conditions where abrupt spatial gradients in temperature can exist.

Non contact thermal measurements were made with an infrared camera with a close up lens made of a standard 50mm lens and additional extension ring. This device allows a spatial resolution of $35 \mu \mathrm{m}$ to be achieved.

\section{EXPERIMENTAL METHOD}

\subsection{Experimental bench}

The experimental bench used is a crossbow system. The machining energy is produced by the impact of a $210 \mathrm{~kg}$ mass on a machining mechanism (Fig. 1), which is mounted on a Hopkinson bar in order to measure the axial component of the machining force.

A calibrated focal plane array monitors the test at a safe distance to avoid contaminants. 


\subsection{Machining mechanism}

The machining mechanism includes a body and a crosshead (Fig. 2) which comes into the body when the mass impacts the machining mechanism. The test specimen is attached to the crosshead, and the body supports a tool. This allows the tool to cut the test specimen and to generate a chip by planing.

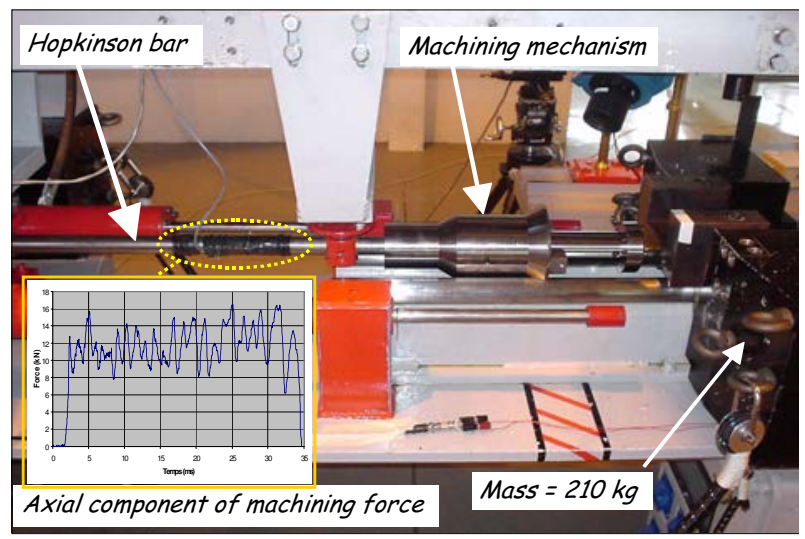

Figure 1: Machining mechanism on crossbow system.

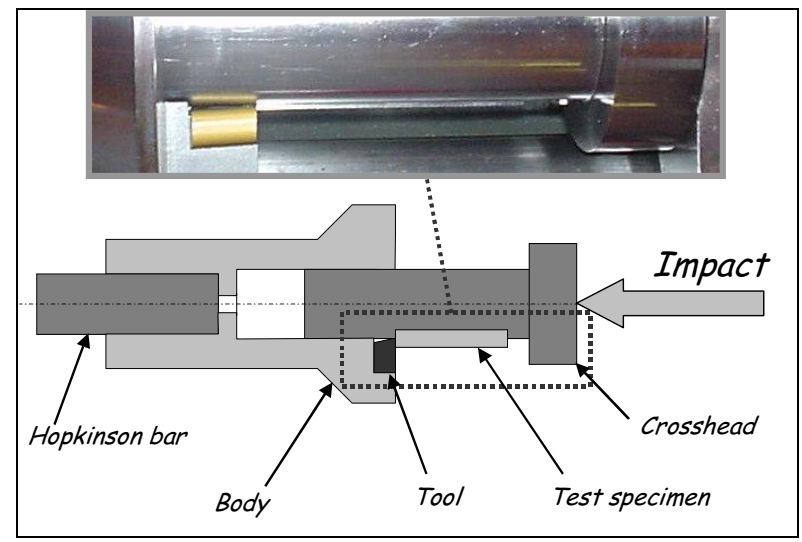

Figure 2: Machining mechanism.

\subsection{Video systems}

For this kind of dynamic situation, the video systems must enable a continuous recording of the cutting operation and the heat phenomena (Fig. 3). Firstly, a high speed camera records the chip flank evolution. The observed surface of the test specimen is previously prepared by chemical attack, in order to make a post-treatment by correlated picture analysis. The pictures are analysed with specific software (ICASOFT from INSA Lyon, VIC 2D from Techlab, CORELLI from LMT Cachan) to determine displacements and strains in the material (Fig. 4).

Secondly, a high speed infrared camera JADE MWIR monitors this zone to study the thermal field variation due to machining. The infrared camera is a 320 × 240 pixel focal plane array using MCT technology. These detectors are known to have high sensitivity and high speed at high temperature. The spectral response within the middle wave band is $3.7 \mu \mathrm{m}$ to $4.9 \mu \mathrm{m}$. In this spectral range both $\mathrm{CaF}^{2}$ and Sapphire windows can be used to protect lenses against contaminants. The detector size is $28 \mu \mathrm{m}$ and the pitch $30 \mu \mathrm{m}$. By selecting an adapted camera configuration without filter alignments were

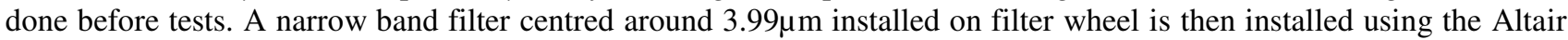
software and remote control. This allows temperature to be increased to $1000^{\circ} \mathrm{C}$. Windowing capability of the FPA limits the number of pixels in order to increase the frame rate. Fixed and random windowing are available to reach different frame rates and fields of view. The test camera specifications are presented in table 1.

\begin{tabular}{|c|c|c|c|c|c|}
\hline $\begin{array}{c}\text { Detector size } \\
\text { (windowing) }\end{array}$ & Filter & $\begin{array}{c}\text { Integration } \\
\text { time }\end{array}$ & Frame rate & $\begin{array}{c}\text { Temperature } \\
\text { range }\end{array}$ & $\begin{array}{c}\text { Spatial resolution } \\
\text { (IFOV) }\end{array}$ \\
\hline $80 \times 60$ & $3.99 \mu \mathrm{m}$ & $50 \mu \mathrm{s}$ & $3200 \mathrm{~Hz}$ & Up to $1000^{\circ} \mathrm{C}$ & $35 \mu \mathrm{m}$ \\
\hline
\end{tabular}

Calibration of the camera is made by the supplier on black bodies. The calibration was made between $5^{\circ} \mathrm{C}$ and $1000^{\circ} \mathrm{C}$ with 6 calibration curves. Note that calibrations are independent of the fame rate. A drift control device within the camera allows compensation of the thermal drift during long tests or to compare tests made on different days.

Nevertheless accurate measurements are limited by emissivity evaluation. A precise evaluation of the temperature variation is not possible because the orientation between the observed surfaces and the camera axis varies, thus affecting the emissivity $\varepsilon_{(\lambda, \theta)}$. Some previous works show that the emissivity was around 0.14 and depends on the chip temperature. The temperature evaluation must then be performed carefully. However, the comparison of the thermal fields between two or more materials is now possible with good precision, and for identical geometric criteria. 


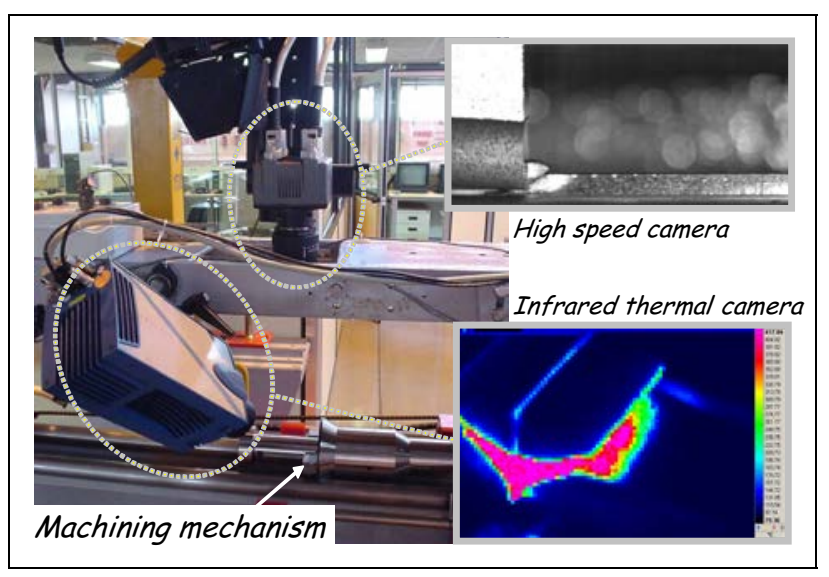

Figure 3: High speed and infrared thermal cameras.
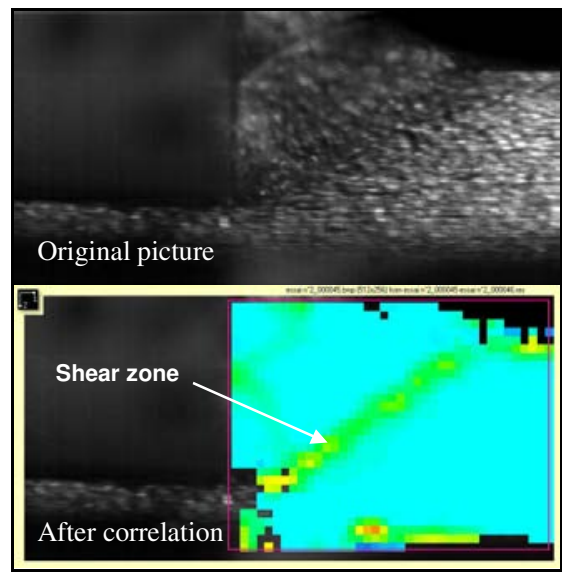

Figure 4: Deformation in shear zone

\subsection{Experimental conditions}

The first tests are made with two austenitic stainless steels: UGINE 4301 and UGIMA 4301. The latter is an improved machinability version of the first steel. The tool material is a 4025 carbide from Sandvik-Coromant. The tool's geometry is modified so as to perform an orthogonal cutting operation (rake angle $\gamma=0^{\circ}$ and clearance angle $\alpha=3^{\circ}$ ). The selected impact speed is $3 \mathrm{~m} / \mathrm{s}$, a sufficient value for a high speed machining condition for these materials, and adequate for the performances of the camera. Altair software controls remotely the infrared camera. The recording of infrared films is controlled and triggered by a TTL signal delivered by the test machine. The workstation uses a standard notebook PC connected with a Dock in station. Recording in full frame format is possible in real time. The acquisition frequency selected was 3200 frames / s for infrared thermal camera (thermal image size 80 x 60 pixels). The picture definitions are chosen to enable the post treatment, and the maximum acquisition frequency is selected. Finally, the depth of cut « $\mathrm{S}$ » is fixed at $2 \mathrm{~mm}$, and the width « a » at $4 \mathrm{~mm}$.

\section{INFRARED CAMERA \& THERMAL RESULTS}

\subsection{Observation during chip formation}

This method allows comparison of the machining of a couple of materials for identical experimental conditions. The observation with the infrared camera gives thermal field during machining on the flank of the test specimen (Figure 5).
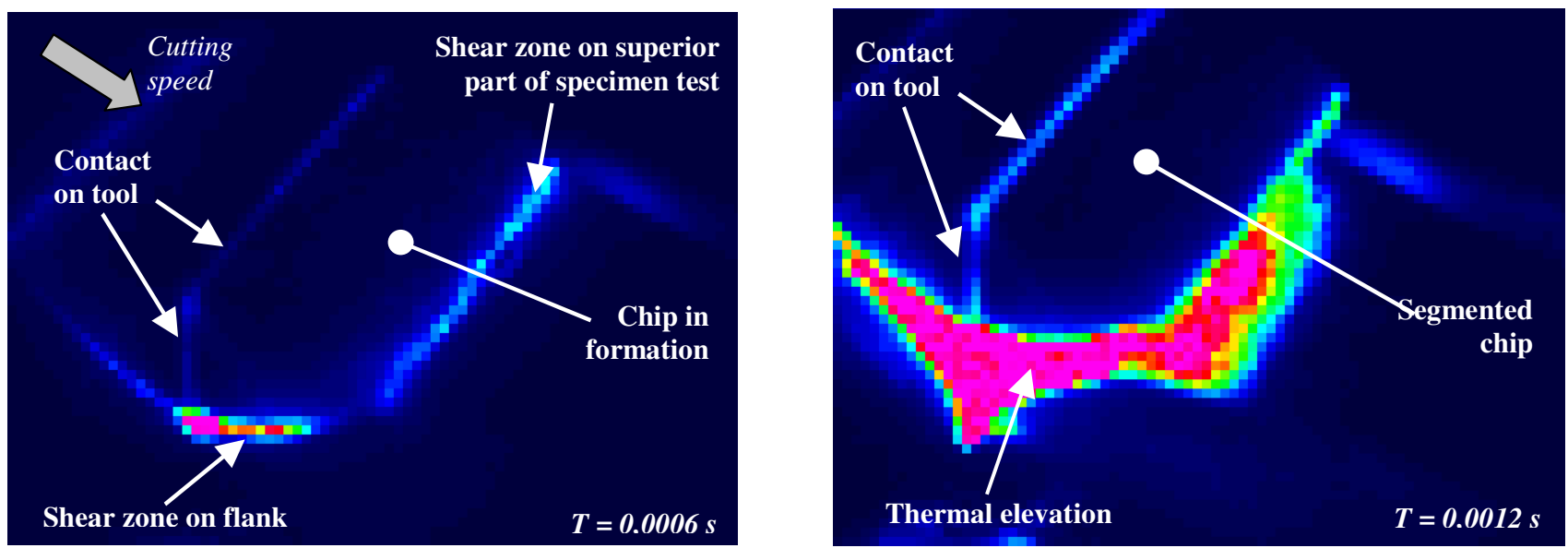

Figure 5: Two steps of thermal evolution in shear zone (left: beginning of segmentation, right: chip segmented), stainless steel UGINE 4301 . 


\subsection{Temperature estimation}

The principal limitation of our method concerns the control of the emissivity $\varepsilon_{(\lambda, \theta)}$. In fact, this parameter is a function of the material, and influenced by the orientation surface / camera axis and temperature. If the orientation between the cutting face of the tool and the axis of the camera is constant, it is not the same for the orientation with the shear band and the plane. However, the Lambert law [10] explains for incidences between 0 and $60^{\circ}$, the maximal diminution of the emissivity is about $20 \%$. When the incidence angle is more than $60^{\circ}$, the emissivity decreases drastically and reaches 0 for $90^{\circ}$. Remaining in the range of 0 to $60^{\circ}$ we can thus evaluate a global uncertainty of $20 \%$ for our measurements.

Figure 6 shows the thermal measurement for the two materials, on the cutting face of the tool (rep. Tool) and the shear zone on the flank, for each chip formation. These measurements are obtained with an emissivity of 0.8 which is an upper bound of the actual one, leading to temperature values which are thus very probably at least underestimated.
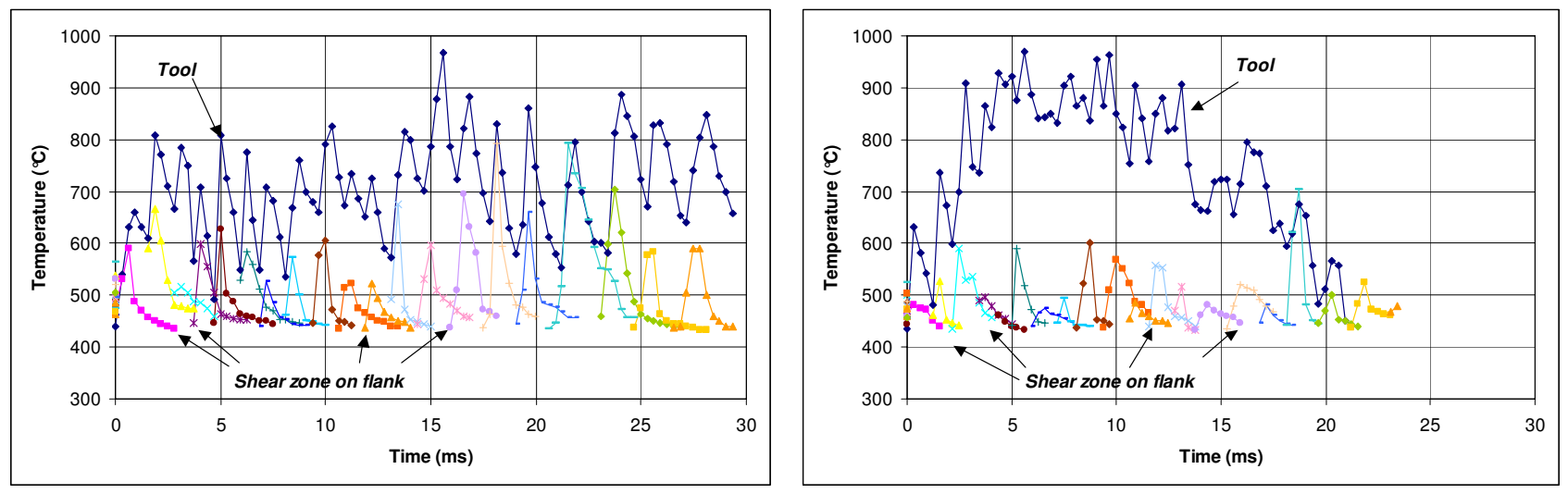

Figure 6: Thermal evolution on tool and shear zone (stainless steel, left: UGINE 4301, right: UGIMA 4301). Emissivity $\varepsilon_{(\lambda)}=0.8$

With these considerations, we can estimate that $800{ }^{\circ} \mathrm{C}$ is the minimal temperature on the cutting face, and $500{ }^{\circ} \mathrm{C}$ that of the primary shear zone.

\subsection{Comparison between two materials}

The comparison between the stainless steels UGINE and UGIMA 4301 shows a higher thermal elevation in the shear band for the first $(+4,5 \%)$, on the mean temperature elevation value obtained for 20 segmented chips (Fig. 7). This observation is repetitive for identical experimental conditions.

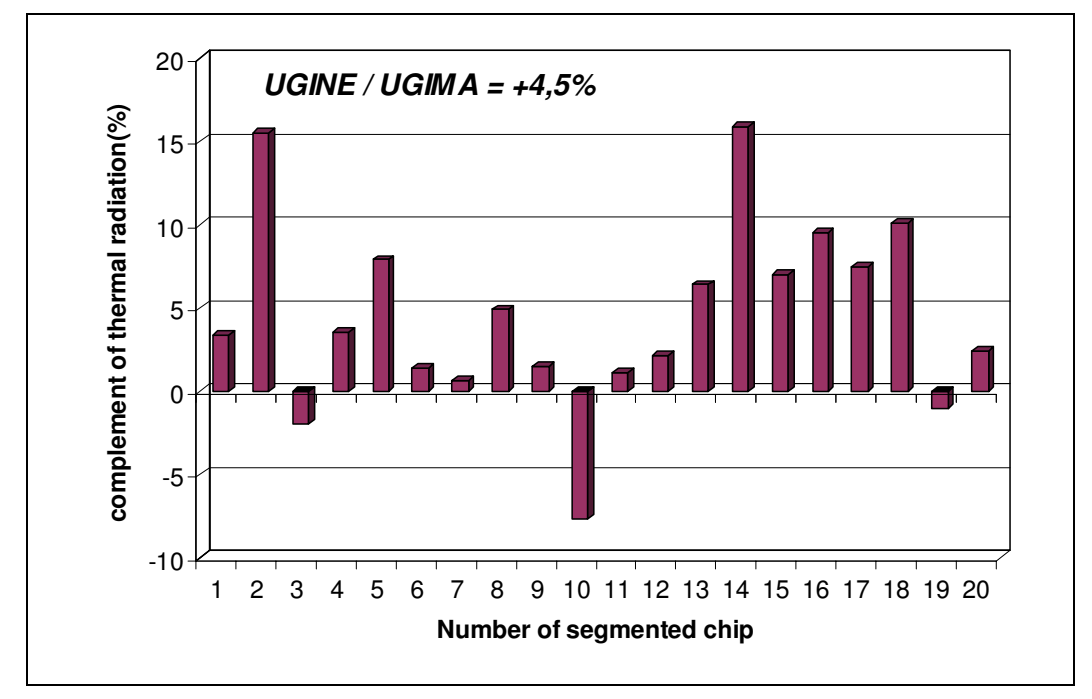

Figure 7: Thermal comparison in shear band, stainless steel UGINE and UGIMA 4301. 


\section{CONCLUSION}

The infrared camera can be used in high speed machining to estimate the temperature field generated in the segmented chip. With some care and with consideration of an uncertainty factor, the absolute temperature determination is possible, but the comparative investigation between materials machined in the crosshead receives same conditions is more exact. However, this method can be optimized with the estimation of the incidence between observed surface and camera axis. Improvement could be possible in using two video cameras for a stereo correlation which could allow us to measure precisely the incidence angle of the infrared camera leading to a better evaluation of the surface emissivity.

1. M. Bäker, Finite-element simulation of segmented chip formation, VII International Conference on Computational Plasticity, COMPLAS (2003).

2. G. Sutter, L. Faure, A. Molinari, N. Ranc and V. Pina, An experimental technique for the measurement of temperature fields for the orthogonal cutting in high speed machining, International Journal of Machine Tools \& Manufacture 43 (2003) 671-678.

3. A. Molinari, C. Musquar and G. Sutter, Adiabatic shear banding in high speed machining of Ti-6Al-4V : experiments and modelling, International Journal of Plasticity 18 (2002) 443-459.

4. P. Sarkulvanich, F. Koppka and T. Altan, Determination of flow stress for metal cutting simulation - a progress report, Journal of Materials Processing Technology 146 (2004) 61-71.

5. G. Sutter, Chip geometries during high-speed machining for orthogonal cutting conditions, International Journal of Machine Tools \& Manufacture xx (2004) 1-8.

6. E.G. Ng, D.K. Aspinwall, D. Brazil and J. Monaghan, Modelling of temperature ans forces when orthogonally machining hardened steel, International Journal of Machine Tools \& Manufacture 39 (1999) 885-903.

7. P.C. Wanigarathne, D. Troutman, A.D. Kardekar, K.C. Ee, G. Poulachon, O.W. Dillon,Jr and I.S. Jawahir, An experimental study cutting temperatures and progressive tool-wear in orthogonal machining with grooved tools, Proceedings of the $7^{\text {th }}$ CIRP International Workshop on Modelling of Machining Operations, ENSAM Cluny, France, May 4-5, 2004, 179-186.

8. A. Molinari, D. Dudzinski, Stationary shear band in high speed machining, Comptes-Rendus de l'Académie des Sciences Paris 315 (II), (1992) 399-405

9. D. Dudzinski, A. Molinari, A modelling of cutting for viscoplastic materials, International Journal of Mechanical Sciences $39 \mathrm{~N}^{\circ} 4$ (1996) 369-389

10. G. Gaussorgues, La thermographie Infrarouge, Editions TEC \& DOC, (1999)

11. H. W. Yoon, M. A. Davies, T.J. Burns, M.D. Kennedy, Calibrated Thermal microscopy of the tool chip interface, Thermosense XXII Vol 4020 (2000).

12. Brenhard Müller, Ulrich Renz, Thermographic measurement of high-speed metal cutting, Thermosense XXIV Vol. 4710 (2002) 